\title{
Effect of Surface Active Pollutants on the Rate of Mass Transfer Controlled Corrosion of Reactors Used in Wastewater Treatment
}

\author{
Eman Radi Sadik, ", ${ }^{1,}$ Taghreed Zewail ${ }^{1}$, Abd El-Aziz Konsowa ${ }^{1}$, Mona Abd El-Latif ${ }^{2}$, \\ Gomma Sedahmed ${ }^{1}$ \\ ${ }^{1}$ Chemical Engineering Department, Faculty of Engineering, Alexandria University, Alexandria, Egypt \\ ${ }^{2}$ Fabrication Technology Department, Advanced Technology and New Materials Research Institute, Alexandria, Egypt
}

Email address:

eman_engprog@hotmail.com (E. R. Sadik), tageng2009@gmail.com (T. Zewail), konsowa2002@yahoo.com (A. El-Aziz K.), amona1911@yahoo.com (M. A. El-Latif),gsedahmed@alex-eng.edu.eg (G. Sedahmed)

${ }^{*}$ Corresponding author

\section{To cite this article:}

Eman Radi Sadik, Taghreed Zewail, Abd El-Aziz Konsowa, Mona Abd El-Latif, Gomma Sedahmed. Effect of Surface Active Pollutants on the Rate of Mass Transfer Controlled Corrosion of Reactors Used in Wastewater Treatment. American Journal of Chemical Engineering. Vol. 4, No. 5, 2016, pp. 92-97. doi: 10.11648/j.ajche.20160405.11

Received: July 22, 2016; Accepted: August 2, 2016; Published: September 9, 2016

\begin{abstract}
The diffusion controlled corrosion of a cooling system composed of an array of vertical tubes attached to the inner wall of a fixed bed reactor containing plastic Raschig rings was studied by a rapid technique which involves the diffusion controlled dissolution of copper in acidified dichromate. Variables studied were solution velocity, Raschig rings diameter, vertical tube height and the presence of surface active agent. The present data were correlated by a dimensionless equation. The presence of surface active agents decreased the rate of mass transfer by an amount ranging from 7.5 to 36.2 depending on the operating conditions. Implications of the present results for the design and operation of built-in cooling systems of fixed bed reactors was highlighted. Also the possible use of the obtained equation in calculating the rate of heat transfer by analogy was discussed.
\end{abstract}

Keywords: Mass Transfer, Heat Transfer, Fixed Bed, Diffusion Controlled Corrosion, Exothermic Reactions, Catalytic Reactors, Heat Exchanger

\section{Introduction}

In view of their high specific area and their high rates of heat and mass transfer fixed bed reactors are used widely in industry to conduct diffusion controlled heterogeneous and catalytic reactions [1-3]. Since most of these reactions are highly exothermic reactions fixed bed reactors are usually fitted with a cooling system in order to (i) protect heat sensitive reactants, products and catalyst against thermal degradation (ii) adjust the reactor temperature at the optimum temperature which corresponds to the highest degree of selectivity and yield. Although cooling jacket surrounding the reactor are economically viable they fail to cool large diameter fixed bed reactors effectively because of the low radial rate of heat transfer which may arise from the low thermal conductivity of the packing [1-3]. A supplementary internal heat exchanger should be used in this case to control reactor temperature efficiently [1-3]. In the present study a cooling system composed of a number of vertical tubes distributed all over the inner wall of a fixed bed reactor was used. Since corrosive solutions are used frequently in fixed bed reactors the metallic cooling system will suffer from corrosion. The aim of the present work is to study the rate of diffusion controlled corrosion of the internal auxiliary cooling system under different operating conditions. Diffusion controlled corrosion of steel in aqueous solution takes place in the $\mathrm{pH}$ range of 4-10, under this condition the rate of steel corrosion is controlled by the diffusion of dissolved oxygen (depolarizer) from the solution bulk to the cathodic sited of the microscopic corrosion cells at the steel surface. In case of copper and its alloys the rate of corrosion 
is controlled by the diffusion of corrosion products from the corroding surface to the solution [4-5]. The present study was carried out using a rapid technique which simulates diffusion controlled corrosion, namely the diffusion controlled dissolution of copper in acidified dichromate [6-7]. The technique has been used widely to study diffusion controlled corrosion and liquid-solid mass transfer at different geometries [8-11]. The importance of the present work lies in the fact that it would make it possible to estimate quantitatively the rate of corrosion and corrosion allowance of the present vertical tube array heat exchanger which is needed in the design stage [12] of fixed bed reactors with rapid temperature control such as immobilized enzymes biochemical reactors catalytic and photocatalytic reactors. In addition the present mass transfer data can be used to predict approximately the outside heat transfer coefficient (by analogy) needed to calculate the rate of heat transfer from the reactor solution to the cooler [13]. The second aim of the present study is to examine the effect of surfactants on the rate of diffusion controlled corrosion of the vertical tube array cooler. Surfactants exist frequently in wastewater containing organic pollutants which are treated by wet oxidation [14] in a catalytic fixed bed reactors, for instance, textile waste solutions, pharmaceutical industry waste solutions, laundry waste solutions, rinse and wash water of restaurants and medical operations, detergents industry wastewater, organic synthesis wastewater, etc.

\section{Experimental Technique}

Figure 1 shows the experimental setup used in the present study. It consisted mainly of 301 glass storage tank, $0.5 \mathrm{hp}$ plastic centrifugal pump, and a vertical cylindrical column. The cylindrical column was $20 \mathrm{~cm}$ inside diameter and $80 \mathrm{~cm}$ in height. The column height was divided into three sections namely: the inlet section, the working section, and the outlet section. The inlet section was packed with inert glass spheres of $2.5 \mathrm{~cm}$ diameter and $30 \mathrm{~cm}$ height. The height of the inlet section was sufficient to calm the flow [15]. The working section consisted of eight vertical copper tubes array which were fixed and distributed uniformly all over the inner wall of the column. Each tube was $2.2 \mathrm{~cm}$ outer diameter and 20 $\mathrm{cm}$ in height. The inner surface of each tube was well insulated by bee's wax. Figure 1 also shows a cross section plan of the cylindrical column and the 8 vertical tubes array regularly distributed all over the inner wall surface of the column and in absence of packing. The working section was packed with inert plastic Raschig rings. The outlet section which had a height of $30 \mathrm{~cm}$ was packed with $2.5 \mathrm{~cm}$ diameter glass spheres. The column was fitted with an overflow weir at the top. The flow line was made of $1.27 \mathrm{~cm}$ inlet and outlet PVC pipes. The solution flow rate was controlled by a bypass and was measured by a stopwatch and a graduated cylinder. The plastic centrifugal pump was used to circulate the solution between the storage tank and the packed bed reactor.
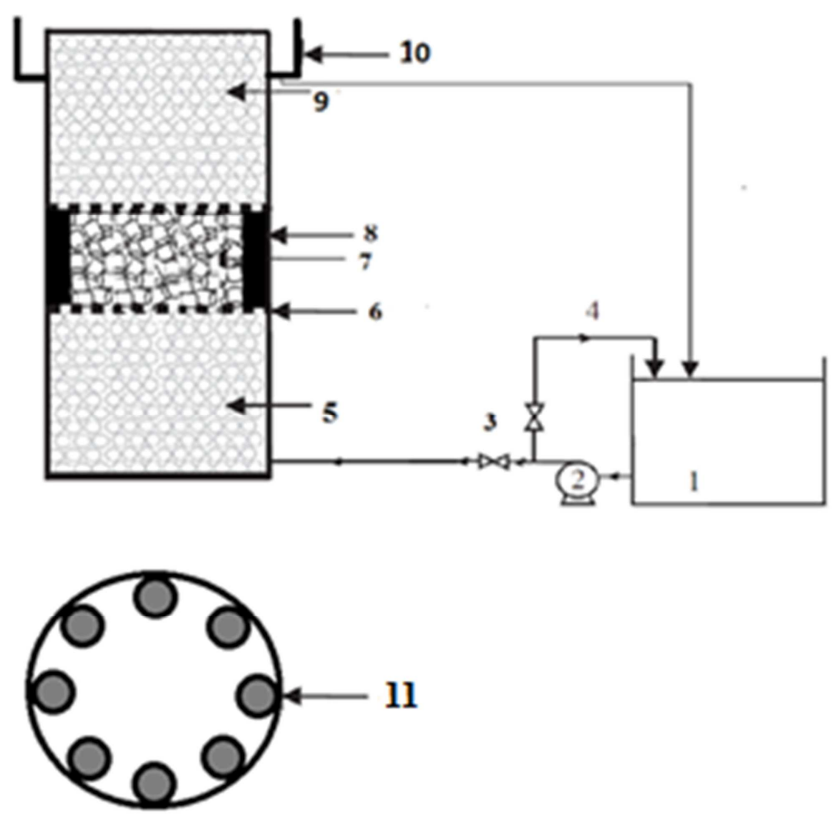

Figure 1. Experimental setup. (1) storage tank,(2) centrifugal pump, (3) valves, (4) bypass, (5) inlet calming section, (6) plastic grid, (7) Raschig rings in working section, (8) copper tubes array, (9) outlet calming section, (10) overflow weir, (11) cross section plan of the vertical tubes array.

All solutions were prepared using A. R grade chemicals and distilled water. Before each run, 251 of the acidified potassium dichromate solution was placed in the storage tank. The concentration of the dichromate solution was measured at different time intervals by withdrawing samples of $10 \mathrm{~cm}^{3}$ of the solution at $5 \mathrm{~min}$ intervals for analysis by the titration against a standard solution of ferrous ammonium sulfate using diphenylamine barium salt as an indicator [16]. All experiments were carried out at temperature $30 \pm 2{ }^{\circ} \mathrm{C}$. The solution viscosity and density used in data correlation were determined using an Ostwald viscometer and density bottle, respectively [17]. The dichromate diffusivity was taken from the literature and was corrected for temperature change [18]. The porosity of the packing used in the present study is listed in Table 1.

Table 1. Porosity of packing used in the present study.

\begin{tabular}{ll}
\hline Raschig rings diameter $(\mathbf{c m})$ & porosity \\
\hline 0.8 & 0.708 \\
1 & 0.735 \\
1.2 & 0.768 \\
\hline
\end{tabular}

\section{Results and Discussion}

The mass-transfer coefficient at outer surface of copper tubes was determined under different conditions from the recirculating batch reactor material balance equation [19-20]:

$$
-\mathrm{Q} \frac{\mathrm{dC}}{\mathrm{dt}}=\mathrm{kAC}
$$

which upon integration yields:

$$
\mathrm{Q} \ln \left(\frac{\mathrm{C}_{\mathrm{o}}}{\mathrm{C}}\right)=\mathrm{kAt}
$$


Figure 2 shows a typical plot of $\ln \left(\frac{\mathrm{C}_{0}}{\mathrm{C}}\right)$ versus t; the masstransfer coefficient under different conditions was calculated from the slope $\mathrm{kA} / \mathrm{Q}$.

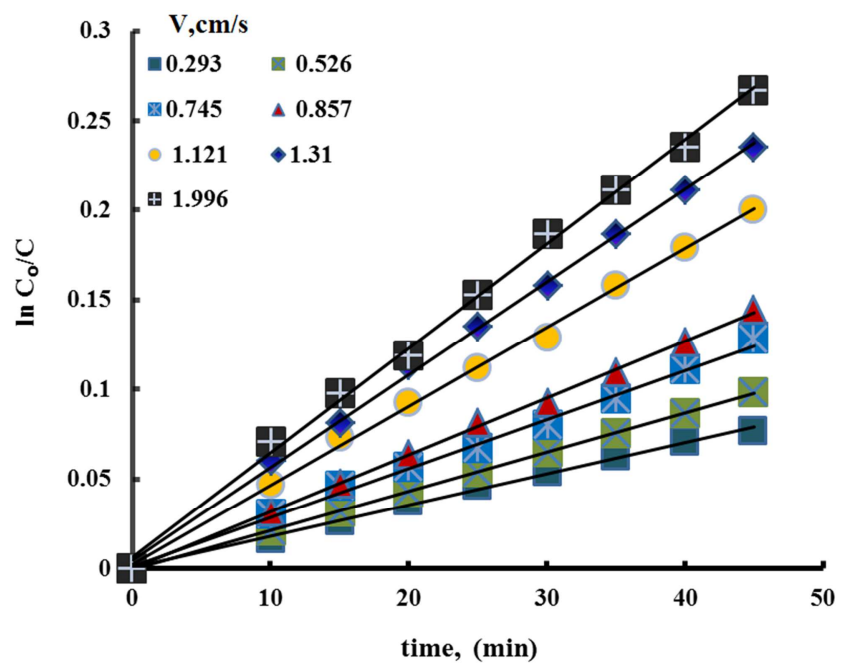

Figure 2. Atypical plot of $\ln \left(c_{o} / c\right)$ versus time at different solution velocities (packing particle diameter $1 \mathrm{~cm}$, tube height $=20 \mathrm{~cm}$ ).

Figure 3 and Figure 4 show the effect of the solution velocity on the mass transferat different packing sizes and different copper tubes active heights respectively. The mass transfer coefficient can be related to solution velocity by the equation:

$$
\mathrm{k} \propto \mathrm{V}^{0.75}
$$

The increase in the mass transfer coefficient with increasing solution velocity may be attributed to the higher degree of turbulence resulting from boundary layer separation as the uprising solution crosses the Raschig rings surrounding the vertical tubes, these turbulences reduce the diffusion layer thickness and increase the mass transfer coefficient $\mathrm{k}(\mathrm{k}=\mathrm{D} / \delta)$ [13]. In a previous study by $\mathrm{M}$. $\mathrm{H}$. Abdel-Aziz, et al [10] who studied the rate of mass transfer of wall of a fixed bed reactor packed with Raschig rings found that the mass transfer coefficient at the inner wall of a fixed bed reactor is proportional to the solution velocity to power $\mathrm{n}$ where $\mathrm{n}$ ranges from (0.63 to 0.73$)$ depending on packing geometries, which is consistent with the present results.

Figure 3 shows that for a given solution velocity the smaller the packing size, the higher the mass transfer coefficient. This is attributed to the fact that as the particle size decreases the bed porosity decreases (Table 1) with a consequent decrease in the area across which the solution flow. According to the continuity equation the interstitial velocity increases with a consequence increase in the mass transfer coefficient at the vertical tubes. Figure 4 shows that for a given solution velocity the mass transfer coefficient decreases slightly as the copper tubes active height increases. This is because increasing the tubes height causes an increase in the developing velocity boundary layer and concentration boundary thickness along the tubes surface, as a consequence the mass transfer coefficient decreases.

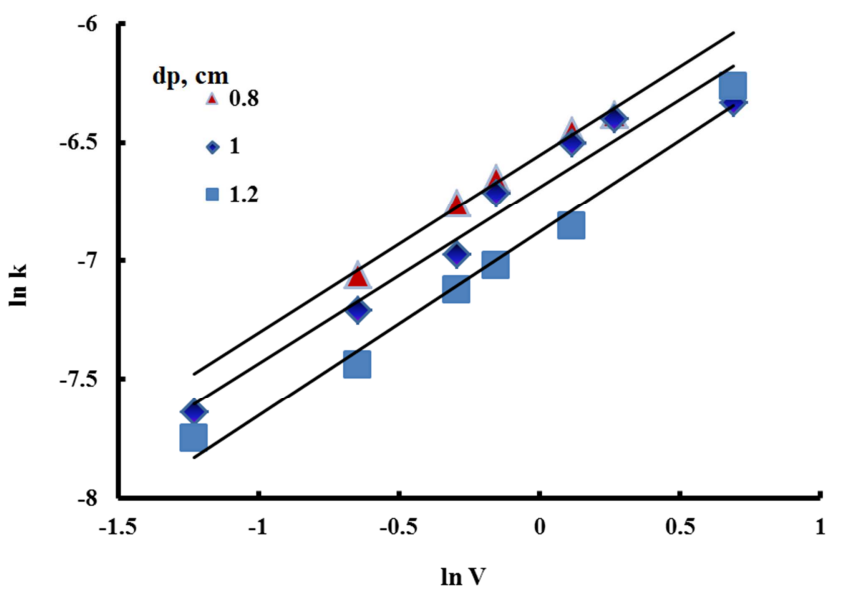

Figure 3. Effect of solution velocity on the mass transfer coefficient at different packing particles diameter.

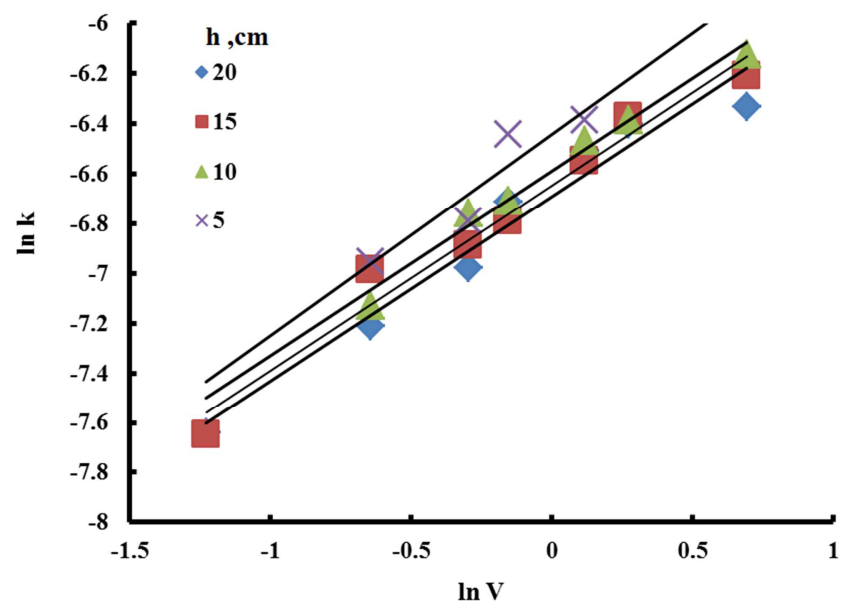

Figure 4. Effect of solution velocity on the mass transfer coefficient at different tube heights.

Figure 5 shows the effect of the solution velocity on the mass transfer coefficient at different surfactant (Triton X100) concentrations. The mass transfer coefficient decreases with increasing surfactant concentration. Table 2 shows the $\%$ reduction in the rate of mass transfer at different solution velocities and different surfactant concentration. The \% reduction ranges from 7.53 to 36.16 depending on the solution velocity and surfactant concentration. The reduction might be attributed to the increase in the interfacial solution viscosity [21] as a result of adsorption of the surfactant molecules on the outer tube surface; the increase in interfacial viscosity gives rise to a corresponding decrease in the effective diffusivity of the reacting ion according to the Stokes-Einstein equation ( $\mu \mathrm{D} / \mathrm{T}=$ const) [18]. Table 2 shows that in general the $\%$ reduction in rate of corrosion decreases with increasing solution velocity, this may be ascribed to the fact that the weakly adsorbed triton molecules are easily dislodged from the metal surface with increasing the shear stress of the flowing solution which increases with increasing solution velocity. The present result is consistence with previous studies which dealt with the effect of surface active agents on the rate of mass transfer [21-22]. 


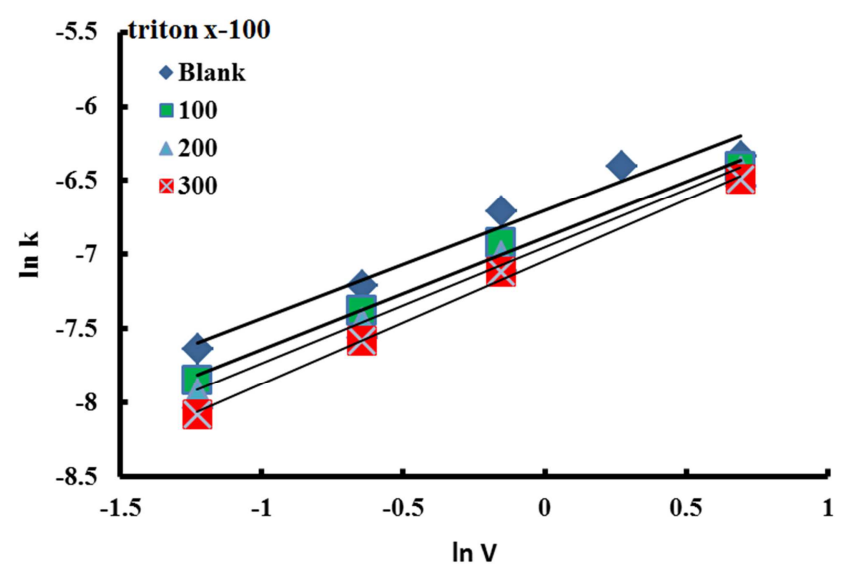

Figure 5. Effect of solution velocity on the mass transfer coefficient at different triton concentrations.

Table 2. \% Reduction in mass transfer coefficient at different solution velocities and different surfactant concentrations.

\begin{tabular}{|c|c|c|c|}
\hline \multirow[b]{2}{*}{ solution velocity, $\mathrm{cm} / \mathrm{s}$} & \multicolumn{3}{|c|}{ Triton 100-conc, ppm } \\
\hline & 100 & 200 & 300 \\
\hline 0.29 & 19.14 & 26.14 & 36.16 \\
\hline 0.53 & 15.62 & 22.13 & 31.47 \\
\hline 0.86 & 18.99 & 26.03 & 33.72 \\
\hline 1.31 & 11.33 & 15.38 & 20.66 \\
\hline 2.00 & 7.53 & 10.21 & 15.00 \\
\hline
\end{tabular}

Mass transfer data correlation:

The present mass transfer data were correlated by using the method of dimensional analysis. For forced convection mass transfer under turbulent flow conditions in fixed bed packed column, the mass transfer coefficient can be related to the governing variables by the following equation:

$$
k=f\left(\mu, \rho, L, V, D, d_{p}, d\right)
$$

Dimensional analysis leads to the following equation:

$$
\frac{\mathrm{kL}}{\mathrm{D}}=\mathrm{a}\left(\frac{\rho \mathrm{VL}}{\mu}\right)^{\alpha}\left(\frac{\mu}{\rho \mathrm{D}}\right)^{\beta}\left(\frac{\mathrm{d}_{\mathrm{p}}}{\mathrm{d}}\right)^{\gamma}
$$

i.e.

$$
\operatorname{Sh}=\operatorname{aRe}^{\alpha} \operatorname{Sc}^{\beta}\left(\frac{d_{p}}{d}\right)^{\gamma}
$$

The constants a, $\alpha$, $\beta$ and $\gamma$ were determined using the present experimental data. Following previous experimental and theoretical mass transfer studies, the value of $\beta$ was fixed at 0.33 [23]. For the present fixed bed column the data were correlated by plotting $\operatorname{lnSh}$ versus $\ln \mathrm{Re}$ at different ring diameter Figure 6 and tubes height Figure 7 respectively. Figure 8 shows a plot of $\ln S h$ versus $\ln (\mathrm{dp} / \mathrm{d})$ at different Re. Figure 9 shows that the present mass transfer data for the condition: $\mathrm{Sc}=1044$ and $148<\mathrm{Re}<4005,0.04<(\mathrm{dp} / \mathrm{d})<.06 \mathrm{fit}$ the following equation:

$$
\mathrm{Sh}=.047 \operatorname{Re}^{0.75} \mathrm{Sc}^{0.33}\left(\frac{\mathrm{d}_{\mathrm{p}}}{\mathrm{d}}\right)^{\gamma-0.95}
$$

with an average deviation of $8.55 \%$.

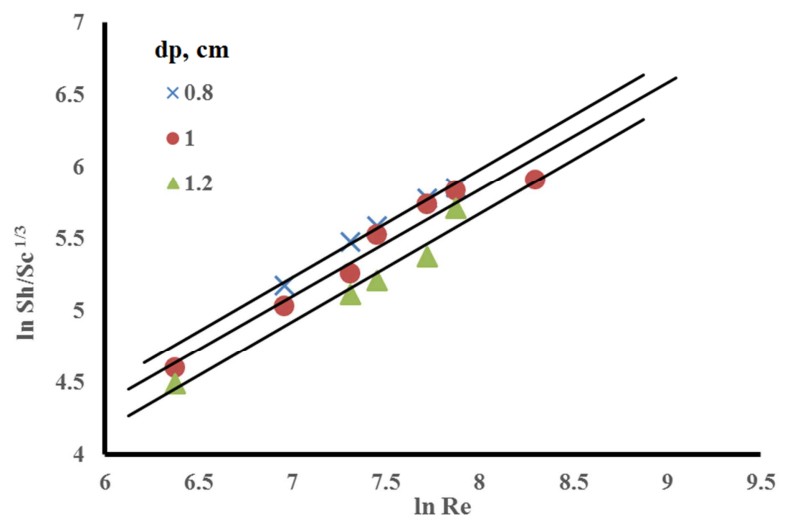

Figure 6. LnSh/Sc 1/3 versus ln Re for different Raschig rings diameters.

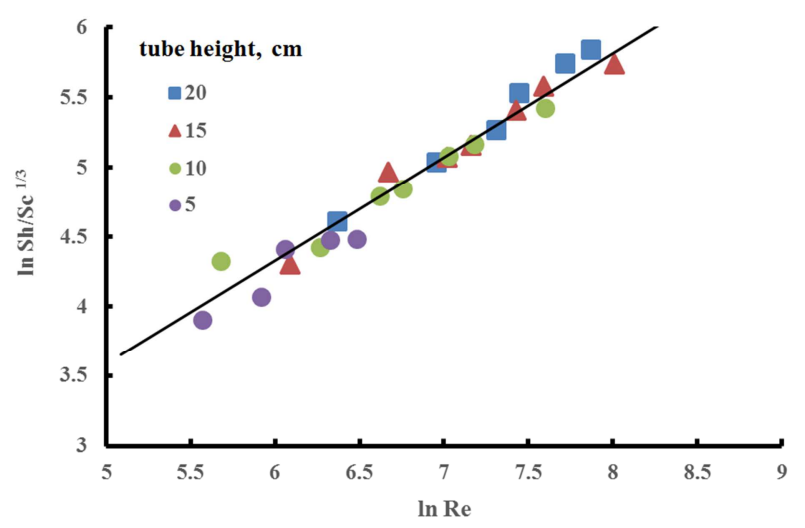

Figure 7. LnSh/Sc 1/3 versus In Re for different tube heights.

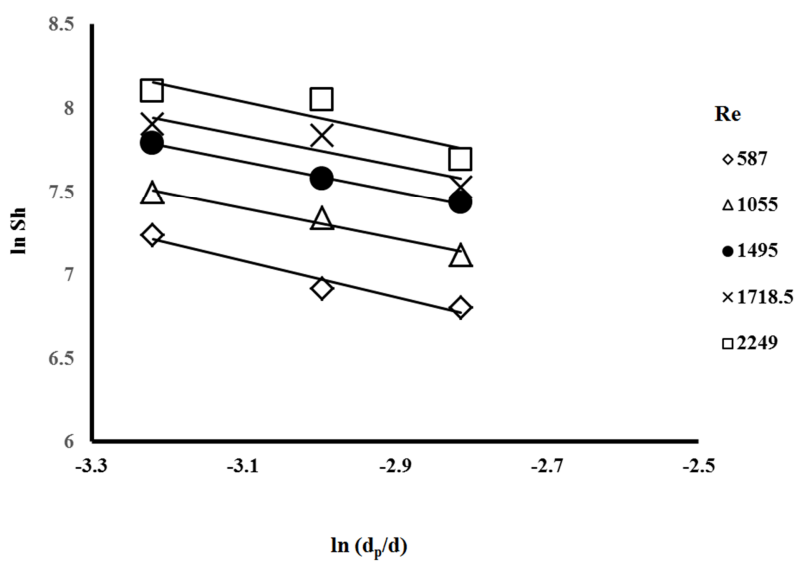

Figure 8. LnSh/Sc 1/3 versus ln (dp/d) for different Re.

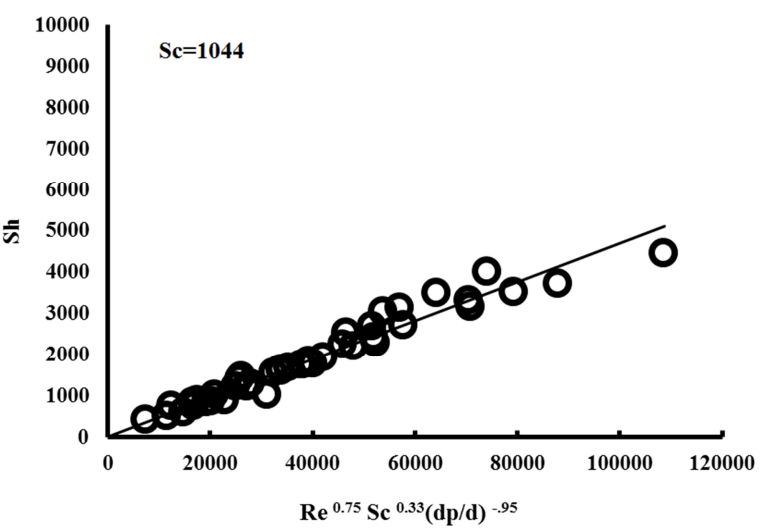

Figure 9. Overall mass transfer correlation. 
It would be of interest to compare the present mass transfer data with the mass transfer data at the wall of a fixed bed reactor packed with inert Rasching rings obtained by $\mathrm{M}$. H. Abdel-Aziz et al [10] who correlated their mass transfer data for the conditions $850<\mathrm{Sc}<1322$ and $80<\mathrm{Rem}<3220$ by the equation:

$$
j=1.6 \operatorname{Re}_{\mathrm{m}}^{-.45}
$$

Where $\mathrm{j}$ mass transfer factor, Rem the modified Reynolds number $(\rho \mathrm{V} \mathrm{dp} / \mu(1-\varepsilon)$ ) and $d p$ is the diameter of the Rasching ring and $\varepsilon$ is the bed porosity. Rearrangement of the eq. (8) in terms of the present dimensionless groups would yield the following equation:

$$
\mathrm{Sh}=1.6(1-\varepsilon)^{0.55}\left(\frac{\mathrm{L}}{\mathrm{d}_{\mathrm{p}}}\right)^{0.45} \mathrm{Re}^{0.55} \mathrm{Sc}^{0.33}
$$

Figure 10 shows a comparison between the present vertical tubes data and the mass transfer data at the wall of fixed bed of inert Rasching rings. Figure 10 shows that the present data lie above the data obtained at the wall of a fixed bed reactor [10]. this is may be ascribed to the fact that the present tubes array occupies higher space than the space that would be occupied by Raschig rings i.e. the presence of the array decreases the available flow area by an amount larger than done by Raschig rings. As a consequence the interstitial solution velocity and the mass transfer coefficient will be higher in case of the present internal tubes array cooler.

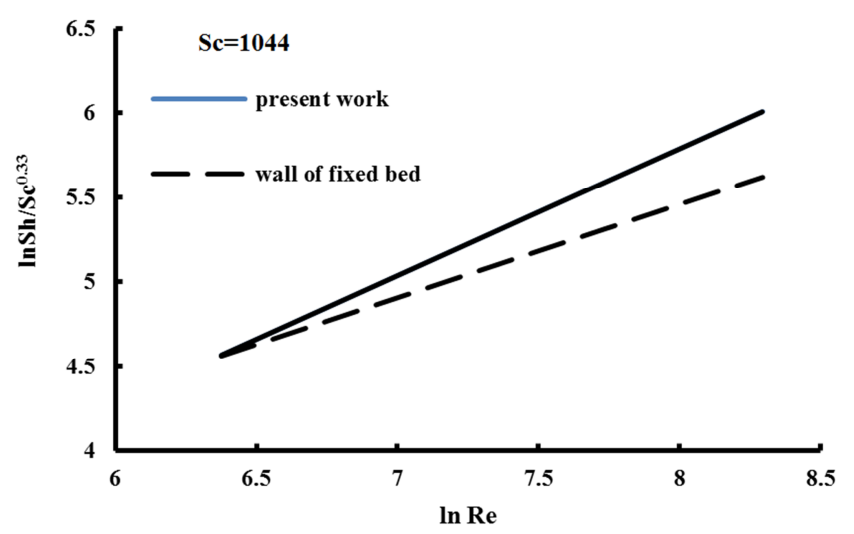

Figure 10. Comparison of the present vertical tubes data and the fixed bed wall data.

\section{Conclusions}

The diffusion controlled corrosion of an auxiliary cooler consisting of an array of vertical tubes distributed all over the wall of packed bed reactor containing inert Raschig rings was studied as a function of the different parameters. The dimensionless mass transfer equation obtained in the present study serve the following useful purposes:

a. Prediction of the rate of diffusion controlled corrosion tubes array cooler and hence the corrosion allowance needed in the design stage of the reactor and its accessories.

b. By the virtue of the analogy between heat and mass transfer the present dimensionless mass transfer equations can be used to predict the outside heat transfer coefficient of the vertical tube cooler, the outside heat transfer coefficient is used to calculate the overall heat transfer coefficient of heat transfer needed to calculate the rate of cooling.

Future studies should deal with the effect of other packing geometries such as cylinders and spheres on the diffusion controlled corrosion of vertical tube array cooling system.

Table 3. Nomenclature.

\begin{tabular}{l|l}
\hline Nomenclature & \\
\hline A & active surface area of copper tubes, cm \\
C & concentration of $\mathrm{K}_{2} \mathrm{Cr}_{2} \mathrm{O}_{7}$ at time $\mathrm{t}, \mathrm{mol} / \mathrm{cm}^{3}$ \\
$\mathrm{C} 0$ & initial concentration of $\mathrm{K}_{2} \mathrm{Cr}_{2} \mathrm{O}_{7}, \mathrm{~mol} / \mathrm{cm}^{3}$ \\
$\mathrm{D}$ & diffusion coefficient, $\mathrm{cm}^{2} / \mathrm{s}$ \\
$\mathrm{D}$ & column inside diameter, cm \\
$\mathrm{dp}$ & packing particle diameter, cm \\
$\mathrm{j}$ & mass transfer j factor $(\mathrm{St} \mathrm{Sc} 0.66)$ \\
$\mathrm{k}$ & mass transfer coefficient, cm/s \\
$\mathrm{L}$ & active height of the copper tubes, cm \\
$\mathrm{Q}$ & solution volume, cm \\
$\mathrm{Re}$ & Reynolds number $(\rho \mathrm{VL} / \mu)$ \\
$\mathrm{Re}$ & modified Reynolds number $(\rho \mathrm{Vdp} / \mu(1-\varepsilon))$ \\
$\mathrm{Sc}$ & Schmidt number $(\mu / \rho \mathrm{D})$ \\
$\mathrm{Sh}$ & Sherwood number, $(\mathrm{kL} / \mathrm{D})$ \\
$\mathrm{t}$ & time, $\mathrm{s}$ \\
$\mathrm{V}$ & solution superficial velocity, cm $/ \mathrm{s}$ \\
$\varepsilon$ & porosity of the bed \\
$\mathrm{M}$ & solution viscosity, g/cm.s \\
$\rho$ & solution density, g/cm \\
$\delta$ & diffusion layer thickness, cm \\
\hline & \\
\hline
\end{tabular}

\section{References}

[1] Y. T. Shah, gas -liquid-solid reactor design, McGraw Hill, New York, 1979.

[2] M. O. Tarhan, catalytic reactor design, McGraw Hill, New York, 1983.

[3] H. H. Lee, Heterogeneous reactor design, Butterworth publishers, New York, 1985.

[4] B. T. Ellison, C. J. wen, Hydrodynamic effects on corrosion, AlChESymp. Ser. vol. 77, 1981, pp. 161-169.

[5] K. J. Kennelly, R. H. Hausler, D. C. Silverman (eds), flow induced corrosion: fundamental studies and industrial experience, NACE, Huston, 1991.

[6] D. P. Gregory, A. C. Riddiford, Dissolution of Copper in Sulfuric Acid Solutions, J. Electrochem. Soc. vol. 107, 1960, pp. 950-956.

[7] A. J. Madden, D. G. Nelson, A Novel Technique for Determining Mass Transfer Coefficients in Agitated SolidLiquid Systems, AIChE J. vol. 10, 1964, pp. 415-430.

[8] M. H. Abdel-Aziz, I. A. S. Mansour, G. H. Sedahmed, Chem. Eng. Process. vol. 49, 2010, pp. 643-648.

[9] M. Zaki, I. Nirdosh, G. H. Sedahmed and M. H. I. Baird, Liquid/solid mass transfer in fixed beds, CHEM ENG TECHNOL. vol. 27, 2004, pp. 414-416. 
[10] M. H. Abdel-Aziz, M. Bassyouni, I. A. S. Mansour, A. Nagi, Wall to liquid mass transport, J IND ENG CHEM. vol. 20, 2014, Issue 5, pp. 2650-2656.

[11] G. H. Sedahmed, The use of drag reducing polymers to combat diffusion controlled corrosion and erosion-corrosion in equipments operated under turbulent flow, Trends Chem. Eng., vol. 9, 2005, pp. 65-72.

[12] J. M. Coulson, J. F. Richardson, R. K. Sinnott, Chem. Eng. (design) vol. 6, Pergamon press, New York, 1983.

[13] F. P. Incropera, D. P. Dewitt, Fundamentals of Heat and Mass transfer, sixth ed., John Wiley \& Sons, New York, 2005.

[14] W. J. Webber, Jr, Physicochemical processes for water quality control, John Wiley \& Sons, New York, 1972.

[15] G. Delaunay, A. Storck, A. Laurent, J. C. Charpentler, Electrochemical study of liquid-solid mass transfer in packed beds with upward cocurrent gas-liquid flow, Ind. Eng. Chem. Proc. Des. Dev, vol. 19, 1980, pp. 514-521.

[16] A. I. Vogel, Text Book of Quantitative Analysis, Longman, London, 1989.
[17] A. Findlay, J. K. Ketchener, Practical Physical Chemistry, Longmans, London, 1965.

[18] E. L. Cussler, diffusion Mass transfer in fluid systems, Cambridge university press, Cambridge, 1988.

[19] F. Walsh, A First Course in Electrochemical Engineering, The Electrochemical Consultancy, Hants, United Kingdom, 1993.

[20] D. J. Pickett, Electrochemical Reactor Design, Elsevier, New York, 1977.

[21] A. Ahmed, G. H. Sedahmed, Effects of surfactants on the rate of Mass transfer at gas evolving electrodes, J. Appl. Electrochem, vol. 19, 1989, pp. 219-224.

[22] A. A. MOBARAK, M. S. E. ABDO, M. S. M. HASSAN, G. H. SEDAHMED, Mass transfer behavior of a flow -by fixed bed electrochemical reactor composed of a vertical stack of screens under single and upward two phase flow, J. Appl. Electrochem. vol. 30, 2000, pp. 1269-1276.

[23] T. K. Sherwood, R. L. Pigford, C. R. Wilke, Mass Transfer, McGraw Hill, New York, 1975. 